\title{
4
}

\section{GIS Applications for Regulatory Compliance}

\section{Uzair (Sam) M. Shamsi}

Many cities in the world especially in the United States and Canada are dealing with regulatory enforcement actions for sewer overflows, such as consent orders and consent decrees. These communities must comply with various mapping, monitoring, inspection, and rehabilitation requirements and develop and implement sewer overflow control plans. To comply with the regulatory requirements, the cities are collecting massive amounts of data on the inventory and condition of their sewer system infrastructure. A dilemma that all stakeholders are facing is how to cost effectively manage this data and monitor what has been accomplished versus what still needs to be done. Geographic Information System (GIS) is a cost-effective technology to manage and analyze these datasets. Above and beyond the conventional GIS mapping of inspection data, integration of field inspection data with a GIS allows development of a sewer rehabilitation decision support system that can be used to plan the rehabilitation work required to control the sewer overflows. With the help of case studies, this chapter describes a GIS-based sewer system inspection and rehabilitation approach.

\subsection{Introduction}

At present, mainly due to age and lack of maintenance, sewer systems of many older cities in developed countries are in critical stages of deterioration. The deteriorated sewer infrastructure is contributing to frequent sewer overflows

Shamsi, U.M. 2009. "GIS Applications for Regulatory Compliance." Journal of Water Management Modeling R235-04. doi: 10.14796/JWMM.R235-04.

(C) CHI 2009 www.chijournal.org ISSN: 2292-6062 (Formerly in Conceptual Modeling of Urban Water Systems. ISBN: 978-0-9808853-2-3)) 
and basement backups (Water Environment Federation, 1999). GIS-based mapping, monitoring, modeling, and inspection and maintenance systems provide a spatial infrastructure management approach that is very effective in prioritizing the infrastructure improvement and maintenance needs and in meeting the regulatory requirements (Shamsi, 2002, Shamsi 2002a, Shamsi, 2005). The most popular applications of GIS for regulatory compliance are described below (Shamsi, 2007).

\subsubsection{Internet GIS}

This application allows us to see a sewer system map of a city overlaid on a wide variety of base maps such as color aerial photographs, property parcels, topographic maps, or as-built drawings. Maintenance crews can access the latest sewer maps (even those updated few hours ago) from their wireless enabled laptops for efficient completion of service requests and work orders. To safeguard the security of sensitive information (e.g. location of large sewers and manholes) in vulnerable areas, site access or access to sensitive data layers can be restricted to pre-screened and pre-authorized users.

\subsubsection{Mobile GIS, GPS, and LBS}

Using GIS in the field for data collection directly into a GIS database is referred to as mobile or field GIS. The ultimate goal of a mobile GIS is to link the maintenance crews with the most recent GIS data to make their job easier and more efficient. Location Based Services (LBS) allow wireless transmission to a GPS location from the field (e.g. a sewer cleaning truck) and display it (even in real time) on a GIS map via wireless Internet.

\subsubsection{Field Inspections}

Mobile GIS technology is being used to inspect manholes, catch basins, inlets, and outfalls; to document smoke and dye tests; and to review TV inspection of sewer pipes. GIS is integrating field inspections, digital photos and videos, and GPS data in one manageable system. "Video mapping" is allowing digital photos and videos to automatically find their correct geographic location on the maps, and users to click on map features to review the inspection results, photos, and videos. Figure 4.1 shows how a user can click on a sewer pipe in an ArcGIS map to watch its CCTV inspection video. This approach implements a paperless system that frees up office space and saves staff time. As a side benefit, digital sewer inspection data can be integrated into hydraulic model calibration (Cheng, et al., 2008). 


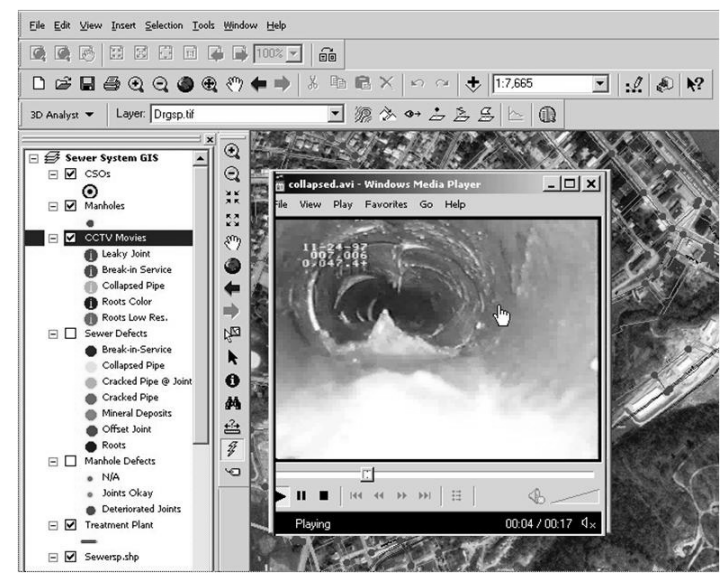

Figure 4.1 Integration of GIS and TV inspection video.

There are five GIS-based approaches for sewer system inspection.

1. Paper-Spreadsheet-GIS: This most basic approach collects inspection data on paper forms, enters inspection data in a spreadsheet, and then links inspection spreadsheet with GIS.

2. Paper-GIS: This approach collects inspection data on paper forms and then enters inspection data in GIS.

3. Database-GIS: This approach collects inspection data in a database (or spreadsheet) and then links inspection database with GIS.

4. All GIS: This approach collects inspection data directly in GIS.

5. Wireless GIS: This most advanced approach collects inspection data directly in GIS and uploads it to a server using wireless technology in real time or near real time.

\subsubsection{Maintenance Management}

A Computerized Maintenance Management System (CMMS) is a software package that maintains a computer database of information about a utility's assets and maintenance operations. This information helps maintenance workers do their jobs more effectively. For example they can determine the last time a manhole was inspected. A typical CMMS package provides 
capabilities for inventory control, asset management, service requests, work orders, preventive maintenance, and routine inspections. GIS-based CMMS packages are most popular because people can see the condition and inspection status of their assets on a map. GIS is used to prepare inspection or maintenance service requests and work orders simply by clicking on an asset such as a sewer pipe or manhole (Shamsi and Fletcher, 2000). This approach simply takes a few minutes compared to the conventional method of locating and copying maps and typing the work order forms which usually takes several hours. Utilities that have successfully implemented GIS-based CMMS packages have seen dramatic improvements in worker efficiency and customer satisfaction.

\subsubsection{Permit Compliance}

CSO permits (e.g. National Pollution Discharge Elimination System [NPDES] permit in the United States) from regulatory agencies generally require periodic physical inspection and maintenance of sewer system infrastructure such as sewer pipes, manholes, pumping stations, diversion chambers, outfalls, inlets and catch basins.

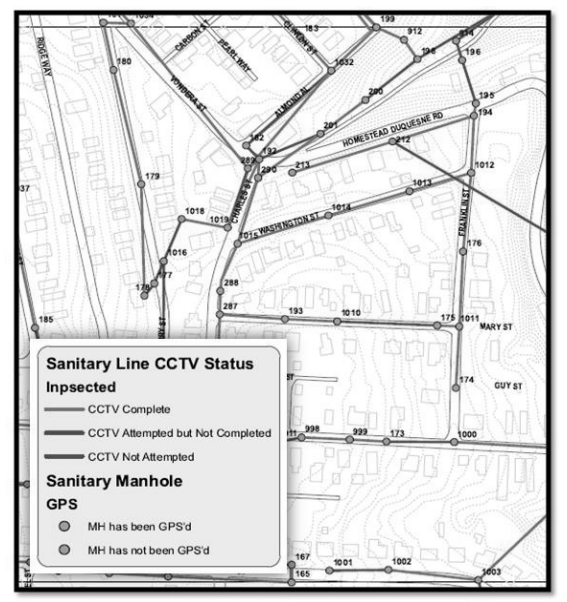

Figure 4.2 CCTV inspection and GPS survey status map.

Using a GIS-based inspection and maintenance system as described above, inspection and maintenance activities can be scheduled and documented for management review, presentations, and permit compliance. 
Inspection and maintenance status maps can be created to show the progress on a monthly, quarterly, or annual basis. For example, these maps can show color-coded pipes for completed vs. remaining TV inspections, or colorcoded catch basins for cleaned vs. remaining structures. Figure 4.2 shows a GIS map for a Consent Order municipality. It shows CCTV inspection status as completed, started but not completed (because of sewer problems), or not started at all. The manhole GPS survey status is shown as completed or not completed.

\subsubsection{Decision Support System}

These applications can be combined to create a sewer system rehabilitation decision support system. A typical application of such a system would be to automatically create projects and bid documents for immediate R5 designated repairs representing the worst type of problems based on National Association of Sewer Service Companies (NASSCO) Pipeline Assessment and Certification Program (PACP) sewer defect codes.

MWH Soft's (www.mwhsoft.com) InfoSWMM CapPlan is a GIS-based decision support software for wastewater infrastructure management and risk assessment. It uses CCTV data analysis to assess both the structural condition of the entire system and the probability and consequence of failure for each asset. Once a system's structural condition has been assessed using CCTV data, CapPlan generates a prioritized list of sewer pipes requiring rehabilitation or replacement. The most cost-effective rehabilitation methodology for each pipe (with one or more major defects or multiple minor defects) is then determined by considering a number of critical factors including hydraulic capacity needs, methodology limitations, physical pipe characteristics (e.g. age, diameter, material), surface restoration, unit costs, length of point repairs to total pipe length, and other utility-specific criteria.

\subsection{Technical Approach}

There are two critical steps in using GIS for regulatory compliance: (i) creating GIS maps of the sewer system and (ii) implementing a GIS-based inspection and maintenance program. Figure 4.3 shows the approach for implementing step (ii).

As shown in Figure 4.3, a GIS-based inspection and maintenance can be implemented by using a commercial GIS software (e.g. ESRI's ArcGIS) that will link the sewer inspection and defect information contained in a database (e.g. WinCan) or spreadsheet to corresponding map features. Such a system 
can provide the Consent Order communities with GIS maps of problematic areas within a sewer pipe network, associated system repair activities (pipe lining, bursting, replacement, manhole repair and replacement, etc.) and the ability to output a series of reports detailing system damage, recommended remedial action, and cost estimates for the repair of damaged structures. Finally, the GIS maps and rehabilitation recommendation reports can be combined to generate what a project manager ultimately needs - bid documents for the repair work (See sample in Figure 4.4).

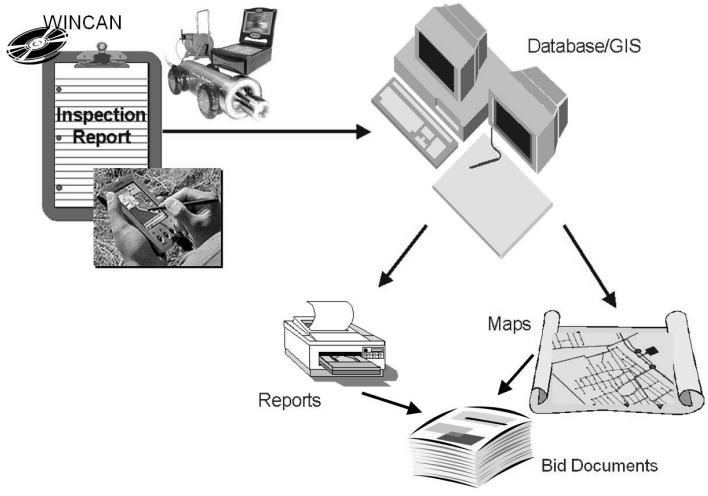

Figure 4.3 GIS-based inspection and maintenance approach.

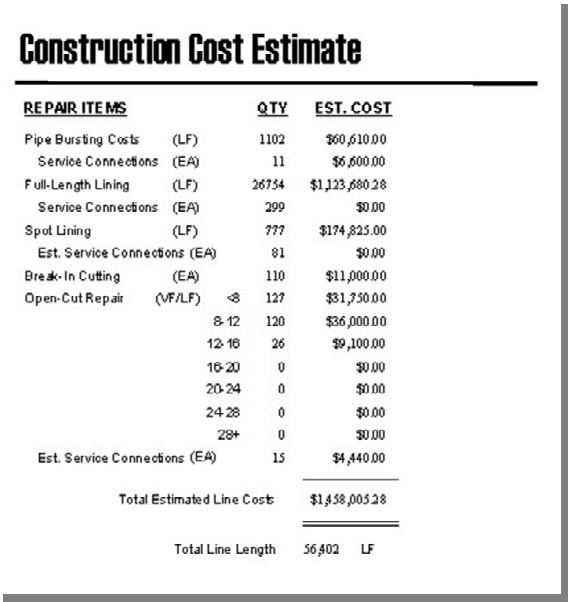

Figure 4.4 Sample GIS-based bid document. 
Figure 4.5 shows a sample process flow chart for developing a GISbased sewer system inspection and maintenance application.

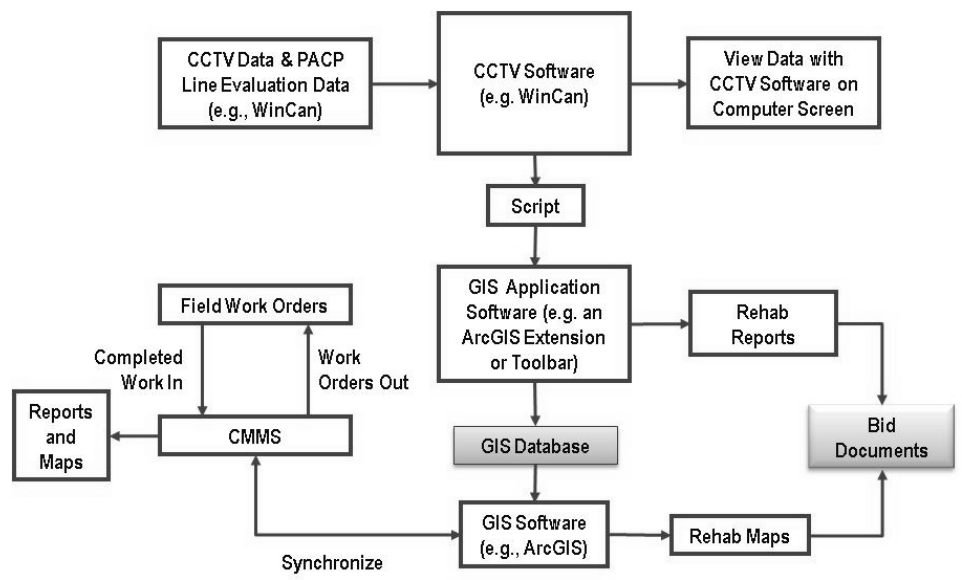

Figure 4.5 Sample process flow chart.

The recommended features of a GIS-based sewer system inspection and maintenance application are described below.

- Interface with CCTV database (e.g. WinCan ${ }^{\mathrm{TM}}$ ).

- Generate QA/QC reports

- Camera data

- GIS data

- Generate Segments of Concern report.

- Apply repair strategies.

- Generate repair schedules.

- Generate GIS maps for rehabilitation work (see sample map in Figure 4.6).

- The data management system generates cost estimates for manhole rehabilitation and line repair work by applying multipliers to unit repair costs. Unit costs are supplied by the project manager and entered into the application. These cost figures may be modified at any time. The system will automatically update all aggregated costs based on the updated values. 
- A variety of reports are automatically generated for use in bid documents and in tracking the rehabilitation effort from identification of a problem area through repair of each line and manhole.

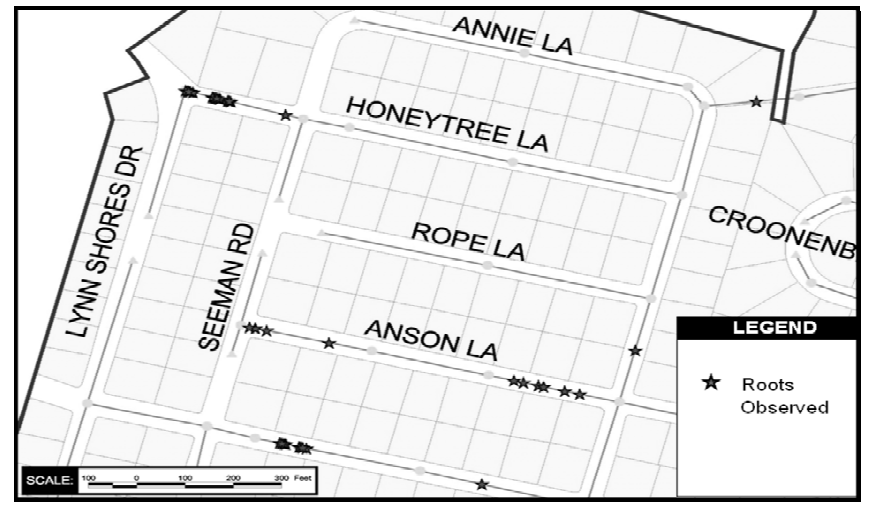

Figure 4.6 Sample rehabilitation map.

\subsection{Case Studies}

\subsubsection{City of Hampton}

The City of Hampton, Virginia has a population of 150,000 and 12,000 manholes and valves. The City conducted a GPS survey to collect coordinates for more than 8,000 manholes located in alleys, buried in yards, or covered with asphalt. The City stored attribute data in an external infrastructure database from GBA Master Series and linked it to ArcView GIS. The GBA software performs infrastructure inventory of manholes and pipes, work order management, and parts inventory management. It can also interface with the City's WinCan system used for CCTV inspection of sewers. The GBA GIS Toolkit, an extension of ArcView GIS, was used to synchronize data consistency between ESRI shapefiles, CAD, and the infrastructure management database. This application provided a GIS map linked to a comprehensive inventory, inspection, and maintenance management software program. The application also provided a graphic 
display of maintenance history and profile plots of user specified sewer segments (ArcNews, 2001).

\subsubsection{Buncombe County}

During the 1990s, the Metropolitan Sewerage District (MSD) of Buncombe County, North Carolina spent more than US\$111 million rehabilitating the most problematic sewer lines in its system. MSD's aggressive sewer rehabilitation program successfully implemented numerous rehabilitation technologies. In 1999, MSD began assessing a method of comprehensive basin-wide rehabilitation. This approach evaluated every pipe in a drainage basin using CCTV footage and engineering analysis. After evaluating this comprehensive basin-wide rehabilitation method for four years, MSD determined that it was overly time- and capital-intensive. Seeking a more efficient and quicker method to fix the system, MSD developed and implemented a new GIS-based rehabilitation method called "pipe rating." The pipe rating method had five main elements: (i) CCTV information, (ii) a defect scoring system, (iii) GIS database software, (iv) Sanitary Sewer Overflow (SSO) history, and (v) engineering analysis. These components were combined to generate specific projects for problem lines (Bradford, et al., 2004; full case study in Shamsi, 2005).

\subsubsection{Allegheny County, Pennsylvania}

Eighty-three (83) communities in Allegheny County have Administrative Consent Orders (ACOs) and Consent Order and Agreements (COAs). ACOs are enforced by the Allegheny County Health Department for the Sanitary Sewer Overflow (SSO) communities. COAs are enforced by the Pennsylvania Department of Environmental Protection (DEP) for the Combined Sewer Overflow (CSO) communities. These communities must complete various mapping, inspection, monitoring, and modeling tasks to develop overflow control plans. Consent orders mandate $1 / 5$ th of sewer system deficiency correction each year until 2010. GIS mapping with specific layers, attributes, and format is required by all consent orders.

Allegheny County Sanitary Authority (ALCOSAN) serves the 83 consent order municipalities including the City of Pittsburgh. ALCOSAN was founded in 1946. It has a service area of approximately 225 square miles $\left(580 \mathrm{~km}^{2}\right)$ with a service population of approximately 900,000 . Figure 4.7 shows the Allegheny County, ALCOSAN's service area, and seven planning basins of ALCOSAN's service area. 


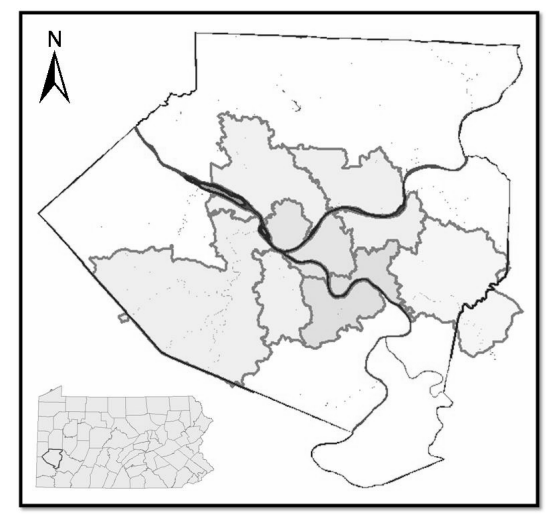

Figure 4.7 Allegheny County and ALCOSAN service area.

ALCOSAN's wastewater treatment plant has a capacity of 200 million gallons per day (MGD) $(875 \mathrm{~L} / \mathrm{s})$ that will be expanded to 275 MGD $(1200 \mathrm{~L} / \mathrm{s})$ in the future mainly for treating additional wet weather flow. On January 27, 2008, ALCOSAN entered into a federal consent decree with the U,S. Environmental Protection Agency (EPA). Under the consent decree, ALCOSAN has agreed to upgrade its sewage systems serving Pittsburgh and 82 municipalities, to pay a US\$1.2-million penalty for past Clean Water Act violations and undertake US\$3 million in environmental projects. The settlement also requires ALCOSAN to submit a wet weather plan to EPA that would resolve a majority of the untreated discharges from the sewer systems by 2026 . The required environmental projects include stream restoration work and other projects to better control storm water runoff.

Pittsburgh Water \& Sewer Authority (PWSA), the largest Consent Order municipality, is using a GIS-based sewer system inspection program for 28,500 manhole inspections, 39,000 catch basin inspections, and 10,200 dye testing inspections. PWSA's inspection application uses ESRI ArcPad mobile GIS software on Panasonic Toughbook field computers. Created using ArcPad Application Builder software, the application records digital photos and videos using Envirosight's Quick View Zoom camera.

\subsubsection{Virginia Beach, Virginia}

The City of Virginia Beach is the most populous city in Virginia and the 41st largest city in the United States, with an estimated population of 435,619 in 2006. The city is listed in the Guinness Book of Records as having the longest pleasure beach in the world. The City has televised over 
$200,000 \mathrm{ft}(610 \mathrm{~m})$ of sewer pipe and conducted over 1,000 manhole inspections. A field inspection database was programmed to collect manhole inspection data. Figure 4.8 shows the manhole inspection database form. The inspection data was exported directly from the field inspection database into the Hansen CMMS (see screenshot in Figure 4.9). This system can use GIS for compliance reporting and monitoring performance measures and creating reports and status maps of sanitary sewer inspection data. Hansen MMS can be synchronized with ArcGIS maps to display inspection data on GIS maps. This application can potentially isolate defect trends, show all PACP level 4 or 5 defects, and group the repair needs for cost effective rehabilitation.

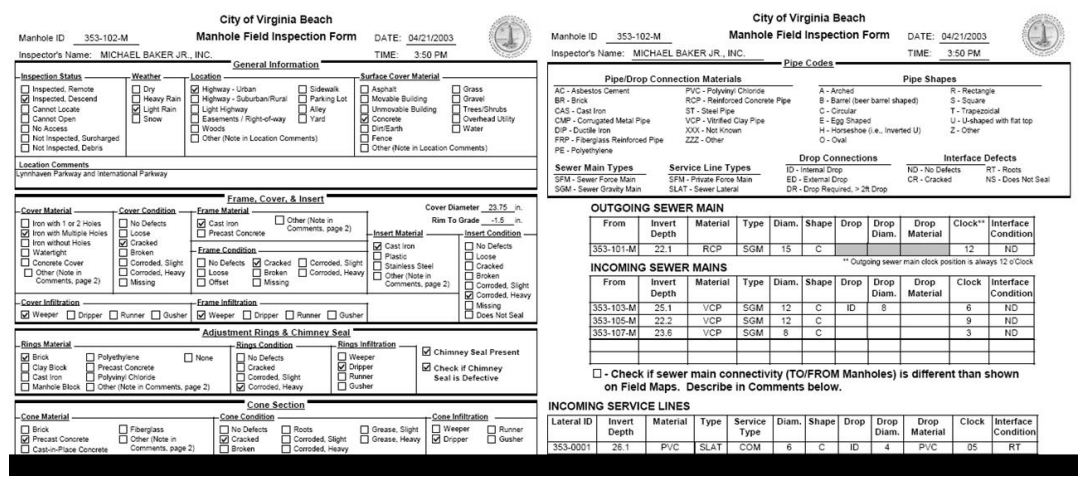

Figure 4.8 Virginia beach manhole inspection form.

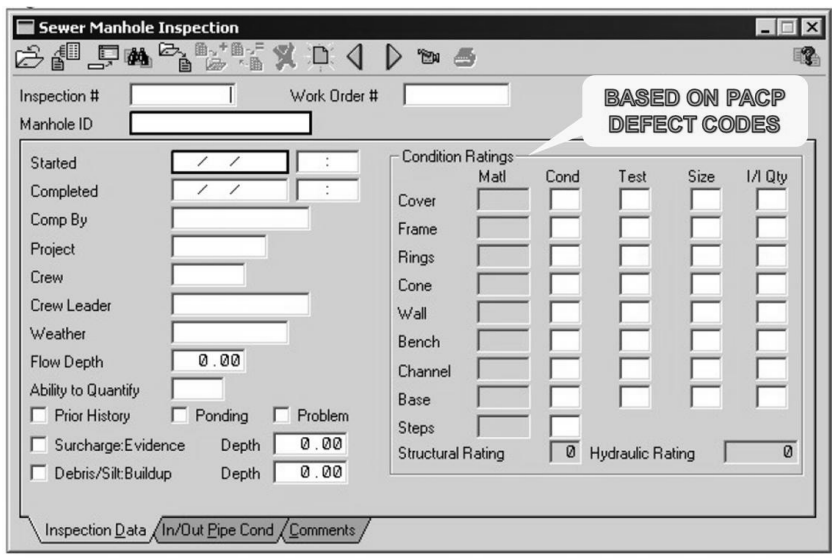

Figure 4.9 Hansen manhole inspection module. 


\subsection{Conclusions}

A GIS-based inspection and maintenance program allows incorporating sewer system defect and rehabilitation data into a single database/mapping environment. Such an application can be used to track and report rehabilitation progress, generate bid documents for rehabilitation work, generate and update reports and maps to meet regulatory requirements, and generate budgetary pricing for repairs and rehabilitation work. Though many cities in the United States are using GIS to map the inspection data, not all of them are using GIS to create rehabilitation maps and projects.

\section{Acknowledgments}

The author would like to thank the Allegheny County Sanitary Authority (ALCOSAN), Pittsburgh Water and Sewer Authority (PWSA), Chester Engineers Inc., and Michael Baker Jr., Inc. for providing the opportunity to work on some of the projects described in this chapter, and/or providing the information on the projects described in this chapter.

\section{References}

ArcNews 2001. GIS Goes with the Flow. ArcNews, Vol. 23, No. 1, Spring 2001, ESRI, 34-35.

Bradford E., Watson R., Mann E., and Konwinski J. 2004. Pipe Rating, Water Environment \& Technology. Water Environment Federation, February, 2004, Vol. 16, No. 2, 39-43.

Cheng, F., G. Barden, E. Burgess and J.A. McGill. 2008. "Integrating Sewer Inspection Data into SWMM Model Calibration." Journal of Water Management Modeling R228-09. doi: 10.14796/JWMM.R228-09.

Shamsi, U.M. and B.A. Fletcher. 2000. "AM/FM/GIS Applications for Stormwater Systems." Journal of Water Management Modeling R206-07. doi: 10.14796/JWMM.R206-07.

Shamsi U.M. 2002. GIS Tools for Water, Wastewater, and Stormwater Systems. 375 pages, ASCE Press, pubs.asce.org/books/

Shamsi, U.M. 2002a. "GIS Applications in Inspection and Maintenance of Collection Systems." Journal of Water Management Modeling R208-14. doi: 10.14796/JWMM.R208-14. 
Shamsi U.M. 2005. GIS Applications for Water, Wastewater, and Stormwater Systems. 413 pages, CRC Press, www.crcpress.com

Shamsi U.M. 2007. Navigating a Smart User Strategy. Water and Wastewater News Online, October 2007, www.wwn-online.com

Water Environment Federation 1999. Prevention and Control of Sewer System Overflows. 2nd ed.; Manual of Practice No. FD-17; Alexandria, Virginia. 
